\title{
Zonal disintegration test of deep tunnel under plane strain conditions
}

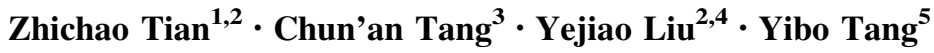

Received: 28 November 2018/Revised: 1 June 2019/Accepted: 7 April 2020/Published online: 28 April 2020

(C) The Author(s) 2020

\begin{abstract}
To investigate the zonal disintegration form of the surrounding rock in deep tunnels, model tests were performed in the simulation set-up of fracture mechanism and support technology of surrounding rock in deep tunnel. The test results illustrate that the first fracture of the surrounding rock occurred at the intersection of the tunnel floor and the side wall. After more serious destruction, the side wall and the vault were destroyed. Although the fracture width of each surrounding rock mass was distinct, they were relatively uniform with a nearly continuous fracture form. The width of the split bodies of the model tunnels (i.e., the annular zonal disintegration area) developed with an increasing load. It was observed from the fitting curves of the data that all radial strain values of the surrounding rock were more symmetric with a smooth fitting curve, and the maximum value occurred near the tunnel wall before reducing instantly. The circumferential strain values were dispersed and the data were inconsistent with the fitting curve, which caused some data to be unreliable. The phenomenon of zonal disintegration was primarily caused by radial tension strain of the surrounding rock. This phenomenon would not extend indefinitely as the rupture range would be limited to a certain extent, because the maximum radial tension strain of the surrounding rock was less than the limiting value.
\end{abstract}

Keywords Deep tunnel $\cdot$ Model test $\cdot$ Crack $\cdot$ Plain strain $\cdot$ Zonal disintegration

\section{Introduction}

Along with the application of underground space development to gradual deep expansion, the phenomenon of zonal disintegration with interval distribution in deep rocks has become a theoretical and practical problem that urgently needs to be solved in the construction of deep of

Zhichao Tian

bailey280@163.com

1 School of Resources \& Civil Engineering, Northeastern University, Shenyang 110819, China

2 Inner Mongolia University of Science \& Technology, Baotou 014010, China

3 Dalian University of Technology, Dalian 116024, China

4 State Key Laboratory of Deep Coal Mining \& Environment Protection, Huainan 232001, China

5 Taiyuan University of Technology, Taiyuan 116024, China zonal disintegration can reflect the nonlinear mechanical characteristics of deep rock mass and the dynamic characteristics of engineering response. This plays an important role in the development of deep underground space. As a result, the phenomenon of zonal disintegration from the perspective of field monitoring, theoretical derivation, model test, numerical simulations and others have been researched.

For field monitoring, the roof interval rupture was first recorded by Adams and Jager (1980) at a 2000-3000 m deep stope in a South African gold mine using a borehole periscope. The phenomenon of zonal disintegration was found by Shemyakin et al. (1986) from a resistivity meter in the site of a deep mine. A multi-point displacement meter was used to monitor the zonal disintegration phenomenon of surrounding rock in a deep roadway in the Jinchuan nickel mining area in China by Fang (1984). Li et al. $(2008,2014)$ discussed the phenomenon of zonal disintegration in different boreholes of surrounding rock in 
tunnel sections, which was monitored using a video camera for borehole drilling in the Dingji Coal Mine of the Huainan Mining area in China. They also found the same phenomenon in the auxiliary tunnel circumference of a deep buried diversion tunnel of the Jinping II Hydropower Station (Li et al. 2016). Analyses of the effects of the initial geostress and evolving stress concentration on deep fracturing were also performed by Feng et al. (2017). Using similar model tests, Zhang and Pan (2015) studied the zonal phenomenon from the perspective of splitting and creep in Brazil. The formation process of surrounding rock rupture in deep tunnels was reproduced by Zhang et al. (2013) through a 3-D geological mechanical model test of similar materials where the maximum load was parallel to the chamber axis.

A number of researchers have explored the mechanism of zonal disintegration. Guzev and Paroshin (2001) considered the non-monotonic change rules of stress as a function of distance from the hole wall by applying nonEuclidean geometry theory (Zhou and Qian 2013). The nonlinear governing equations for the phase transition model of the deep surrounding rock were analyzed by Chen et al. (2017). Zhou et al. (2010, 2013) obtained the residual strength of the rupture zone, provided the width and numbers of the fracture and the non-ruptured zones, and introduced a strength criterion for deep rock mass. A new strength criterion for deep rock mass was derived by Zhang and Zhang (2011) based on fracture mechanics. A mathematical model of zonal disintegration of rocks around a deep-level excavation was developed by Mirenkov (2014). Reuter et al. (2015) described a model for rock failure around breakage headings in coal mines based on the 2-D problem from the theory of creep with finite strains. Numerical simulation methods have also been incorporated to study this problem. For example, the zonal disintegration of deep rock mass was studied using different numerical simulation software and computational procedures by Geng (2010), Gao et al. (2010), Wang et al. (2013, 2016).

Although some research achievements have been accomplished, the study of the evolution law and influencing factors for the zonal disintegration of rock mass have not been systematic or comprehensive; only some empirical and approximate formulas for parameter calculations have been developed (Song 2012; Chen 2016).

Therefore, to study the fracture mechanism of deep rock mass under high stress conditions, physical tests of zonal disintegration under plane strain conditions were performed for this work in a deep straight-wall arch-top tunnel using the simulation test device for studying the fracture mechanism and support technology of surrounding rock in deep tunnel. The failure form and the strain characteristics of the surrounding rock in the deep tunnel were the main research objectives. This study can further enrich related research results of zonal disintegration in deep rock mass while providing an experimental means and technological support for the basic theory and key technology research of geological disaster prevention in deep mine engineering (Chen et al. 2018).

\section{Experimental methods}

\subsection{Experiment set-up}

The zonal disintegration test of a deep straight-wall archtop tunnel under plane strain conditions was considered through "the simulation set-up of fracture mechanism and support technology of surrounding rock in deep tunnel" (Fig. 1) from the China State Key Laboratory of Deep Coal Mining \& Environment Protection (Yuan et al. 2014). The hydraulic loading and control system in this experimental device was composed of a servo oil source, high-precision static servo hydraulic control system, and other components. The device can simulate the crustal stress environment of deep tunnels at depths of approximately $1000 \mathrm{~m}$. In this case, the tunnel deformation can be measured and the failure pattern and process of the surrounding rock in the tunnel can be observed macroscopically. The device enables failure contrast testing of the surrounding rock in deep tunnels under the same test conditions. The primary equipment is designed to be modular for easy management and maintenance.

\subsection{Model test hypothesis}

The actual project is extremely complex; thus, the complete, comprehensive, and realistic simulation of actual situations is difficult. As a result, the design of the model

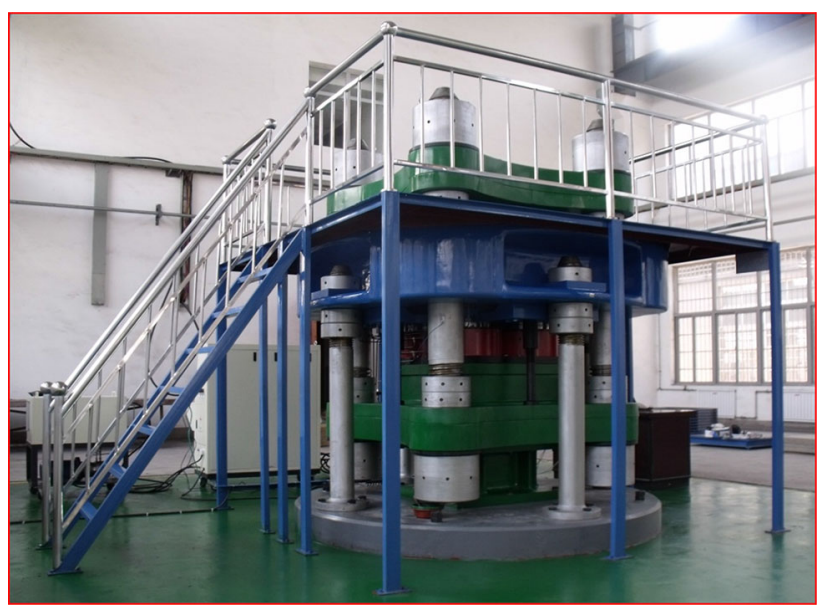

Fig. 1 Simulation test device to study the fracture mechanism and support technology of surrounding rock in a deep tunnel 
test required the following simplifying assumptions (Qian et al. 2009, 2011, 2012; Shou et al. 2018, 2017):

(1) Only the high crustal stress of the deep rock mass was considered.

(2) The rheological properties of the materials were not considered, while also ensuring the test times for each model were the same.

(3) The influence of high temperatures on the destruction of the deep rock mass was not considered.

(4) The simulated primitive rock mass was a homogeneous, continuous, isotropic, medium-strength rock mass, and the effects of adverse geological factors, such as joints, faults, and groundwater, were not considered (Chen et al. 2013).

\subsection{Materials}

Systematic research on the stress deformation and zonal disintegration mechanism of surrounding rock in deep tunnels should be considered experimentally due to the different tunnel shapes, crustal stresses, and loading and unloading methods. However, space constraints only allowed experimental results for zonal disintegration from the deep straight-wall arch-tunnel under plane strain conditions. To solve the similarity problem in the model tests, the geometric and stress similarity conditions were considered through the application of the Froude similarity criterion (Yuan et al. 2014).

\subsubsection{Size of deep prototype tunnel and model tunnel}

The buried depth of the prototype tunnel $H$ was $1000 \mathrm{~m}$, the density of the rock mass $\rho$ was $2.4 \times 10^{3} \mathrm{~kg} / \mathrm{m}^{3}$, the vertical initial crustal stress load generated from the selfweight of the rock mass $P_{\mathrm{V}}^{0}$ was $24 \mathrm{MPa}$, the coefficient of horizontal pressure $N$ was $1 / 3$, and the horizontal crustal stress load generated by the self-weight of the rock mass $P_{\mathrm{H}}^{0}$ was $8 \mathrm{MPa}$. The class of original rock mass is identified as class II, and its uniaxial compressive strength $R_{\mathrm{c}}$ ranges from 30 to $60 \mathrm{MPa}$; Thus, the value of $40 \mathrm{MPa}$ was selected for the tests. The side wall height of the prototype straight-wall arch tunnel was $1.5 \mathrm{~m}$, the arch height was $1.5 \mathrm{~m}$, and the tunnel width was $3 \mathrm{~m}$, as shown in Fig. 2a.

Theoretically, a larger model body gives a smaller model tunnel, which causes a smaller stress influence for the loading boundary on the surrounding rock in the tunnel. Therefore, the geometric similarity coefficient was taken as 1:15 in this paper. The body size of the test model was $100 \mathrm{~cm} \times 100 \mathrm{~cm} \times 40 \mathrm{~cm}$, the side wall height of the model straight-wall arch tunnel was $10 \mathrm{~cm}$, the arch height

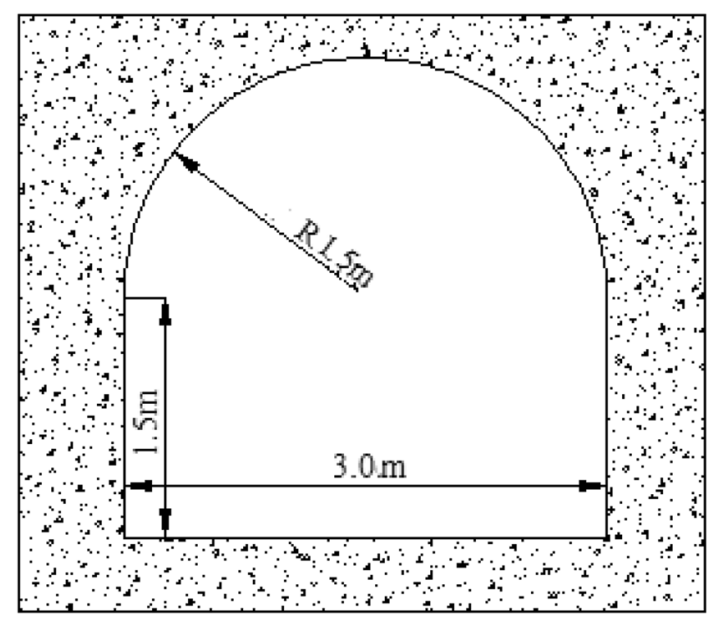

(a)

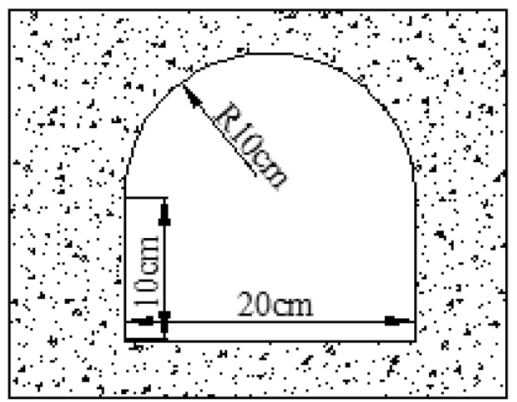

(b)

Fig. 2 Cross sections of the a archetypal tunnel and $\mathbf{b}$ model tunnel

was $10 \mathrm{~cm}$, and the tunnel width was $20 \mathrm{~cm}$, as shown in Fig. 2b.

\subsubsection{Selection of model material}

The similarity coefficient of the stress was chosen as 1:20. Low-marked cement mortar was selected as the simulation material for the rock mass with a weight ratio for the cement: sand: water of 1:14:1.4. The model was formed using the tamping method. The compressive strength of the model material was $2.28 \mathrm{MPa}$. The mechanical parameters of the original rock and the simulation materials are shown in Table 1 (Yuan et al. 2014).

\subsection{Experimental conditions}

Three models were built for the tests and labeled as M1, M2, and M3. The vertical load of each model was represented as $P_{\mathrm{V}}^{0}$, the coefficient of horizontal pressure $N$ was $1 /$ $3\left(P_{\mathrm{H}}^{0}=\frac{1}{3} P_{\mathrm{V}}^{0}\right)$, the plane strain condition was selected, and the uniaxial compressive strength was represented as $R_{\mathrm{c}}$ with a value of $2.28 \mathrm{MPa}$. The loads of the three model tunnels are shown in Fig. 3. After the excavation of the three model tunnels, the maximum load tests were 
Table 1 Mechanical parameters of the original rock and the simulation materials

\begin{tabular}{|c|c|c|c|c|c|c|c|}
\hline Name & $\begin{array}{l}\text { Compression } \\
\text { strength } \\
R_{\mathrm{c}}(\mathrm{MPa})\end{array}$ & $\begin{array}{l}\text { Tensile } \\
\text { strength } \\
R_{\mathrm{t}}(\mathrm{MPa})\end{array}$ & $\begin{array}{l}\text { Cohesion } \\
C(\mathrm{MPa})\end{array}$ & $\begin{array}{l}\text { Internal friction } \\
\text { angle } \\
\Phi\left({ }^{\circ}\right)\end{array}$ & $\begin{array}{l}\text { Modulus of } \\
\text { elasticity } \\
E(\mathrm{GPa})\end{array}$ & $\begin{array}{l}\text { Poisson } \\
\text { ratio } \\
\mu\end{array}$ & $\begin{array}{l}\text { Density } \\
\rho\left(\mathrm{kg} / \mathrm{m}^{3}\right)\end{array}$ \\
\hline $\begin{array}{l}\text { Class II original rock } \\
\text { mass }\end{array}$ & 40 & 2.7 & 2.0 & 50 & 20 & 0.25 & $2.4 \times 10^{3}$ \\
\hline $\begin{array}{l}\text { Required simulation } \\
\text { material }\end{array}$ & 2.0 & 0.14 & 0.1 & 50 & 1.0 & 0.25 & $1.8 \times 10^{3}$ \\
\hline $\begin{array}{l}\text { Selected simulation } \\
\text { material }\end{array}$ & 2.28 & 0.3 & 0.8 & 54 & 0.63 & 0.25 & $1.8 \times 10^{3}$ \\
\hline
\end{tabular}

performed under plane strain. The large and small loads were successively added in equal proportions.

\subsection{Layout of strain measurement points in the model block body}

To reduce the boundary effects of the model, all strain measurement points were arranged on the middle section of the model thickness. Two strain gauges were arranged at each measuring point along the horizontal and vertical directions. There were 64 measuring points and 128 strain gauges in a given model. The arrangement of the strain measurement points in the model is shown in Fig. 4.

In the horizontal direction of the model, a JZQ-E-type uniform pressure loader was used to load the model boundary. The side pressure coefficient $N$ was 1 , and the model was loaded vertically with four longitudinal control cylinders, which were controlled using a JSF-III/60-4-type high-precision static hydraulic servo control table.

\section{Results analysis of zonal disintegration tests}

\subsection{Excavation conditions of models}

The excavation conditions for the M1 model were as follows: (1) the load was $1.44 \mathrm{MPa}$ and was applied uniformly seven times; (2) the maximum load $P_{\mathrm{Vmax}}$ after the excavation was added to $5.91 \mathrm{MPa}$, which was 2.59 times larger than $R_{\mathrm{c}}$.

The excavation conditions for the M2 model were as follows: (1) the load was $4.94 \mathrm{MPa}$ with a uniform load and applied eight times; (2) after the load was completed, the tunnel was excavated in full sections, which was completed four times. As the cavern began to be damaged during the process, a method for rapid excavation was adopted to ensure the cavern could be formed. The tunnel shape was no longer carefully trimmed after each step of the excavation was completed; that is, the tunnel excavation on the nether layer would begin. Tunnel cracks parallel to the hole axis at the foot of wall formed when the excavation depth was over $20 \mathrm{~cm}$; (3) the maximum load $P_{\mathrm{V} \max }$ after excavation was increased to $6.32 \mathrm{MPa}$, which was 2.77 times larger than $R_{\mathrm{c}}$.

The excavation conditions for the M3 model were as follows: (1) the load was added to the maximum load of 5.63 MPa uniformly 14 times, which required $10 \mathrm{~min}$ each time to stabilize the pressure; (2) after the tunnel on the upper layer was excavated, the tunnel excavation on the nether layer occurred without careful repair of the tunnel wall; (3) under plane strain conditions, the load was kept steady to guarantee pressure stability for approximately $5 \mathrm{~h}$.

\subsection{Results analysis of tunnel fracture}

\subsubsection{Fracture forms of model tunnels}

The tunnel fracture forms for the M1 and M2 models are shown in Fig. 5. The figure shows the tunnel fractures for the M1 and M2 models all occurred at the side wall, while the vault and floor remained intact. The fractures at the side wall were all from the bottom area and expanded upwards with a slip line. The fractures finally disappeared at approximately the same level in the arches. There were six cracks on the left and right sides of the walls. The width of the split body gradually developed with increased distances from the foot of the wall. The increased force of the tunnel caused the width of the split body for the M2 model to be larger than the M1 model. The slip lines for the M2 model were not developed at the arch but could still be observed.

The fracture form of the M3 model tunnel is shown in Fig. 6. The figure shows several longitudinal cracks parallel to the hole axis at the foot of the left and right walls while the pressure was stabilizing; the cracks shrank in the direction of the hole. The warping deformation at the foot of wall and in the wall of the hole occurred towards the hole, causing part of the wedges to expand and gradually break away from the wall of the hole before finally 


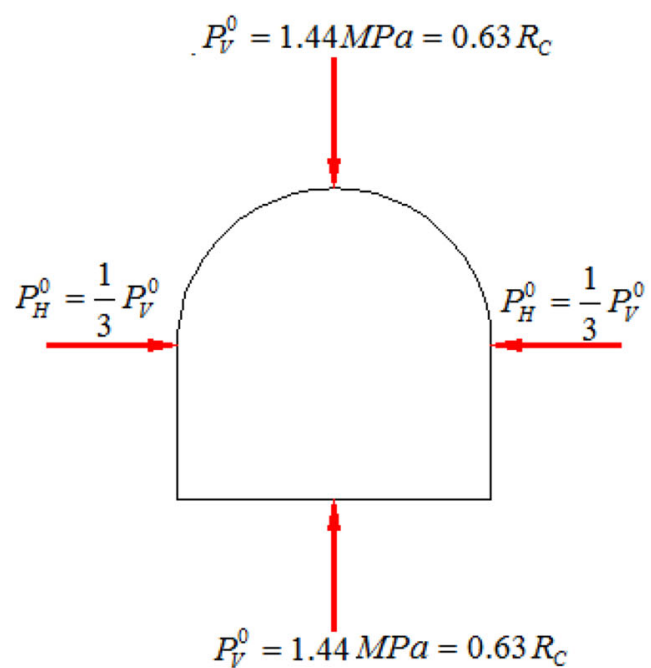

(a) $\mathrm{M} 1$

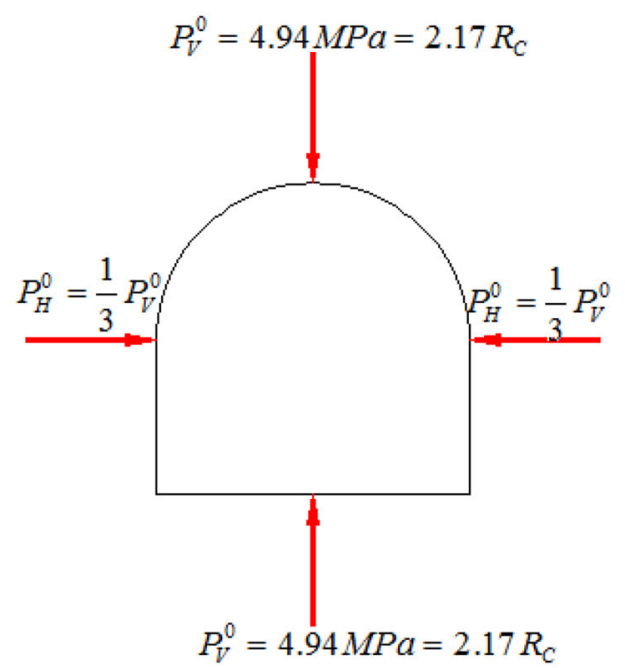

(b) $\mathrm{M} 2$

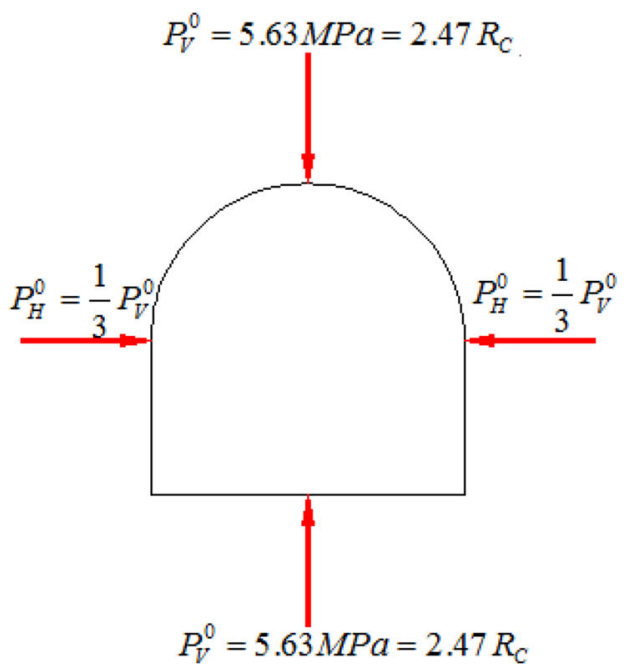

(c) $\mathrm{M} 3$

Fig. 3 Comparison of loads for the a M1, b M2, and c M3 model tunnels

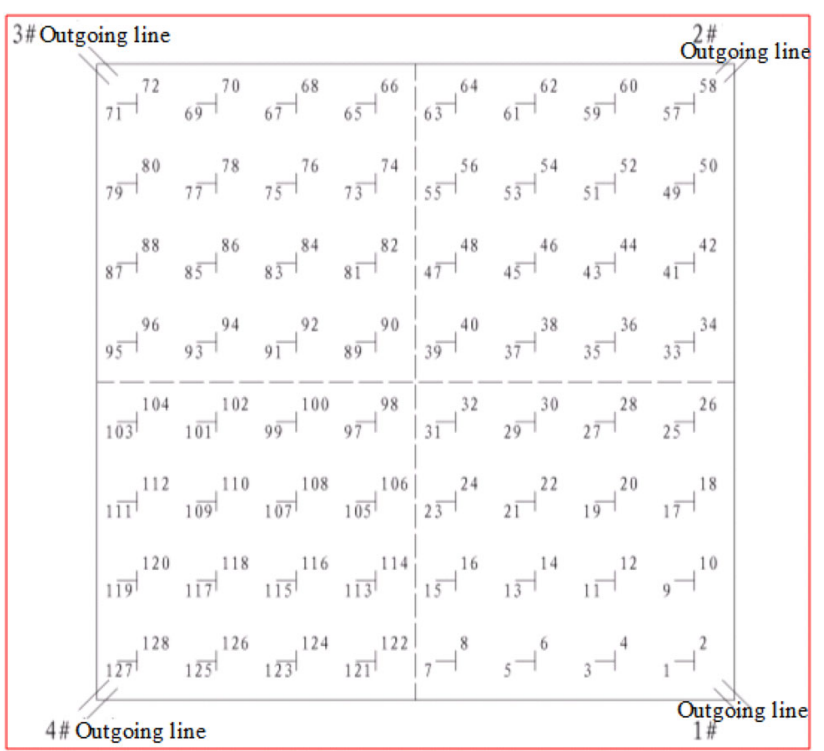

Fig. 4 Layout of the strain measuring points in the model

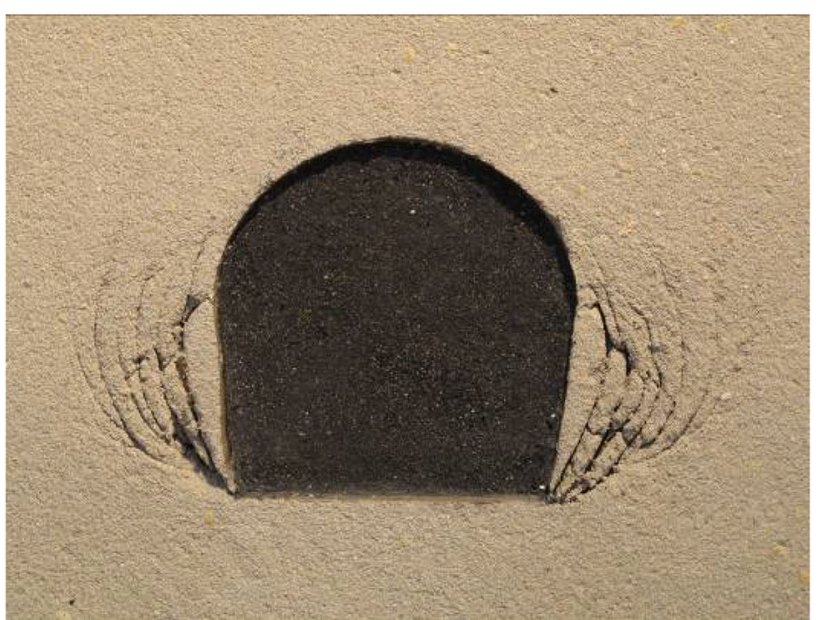

(a) M1

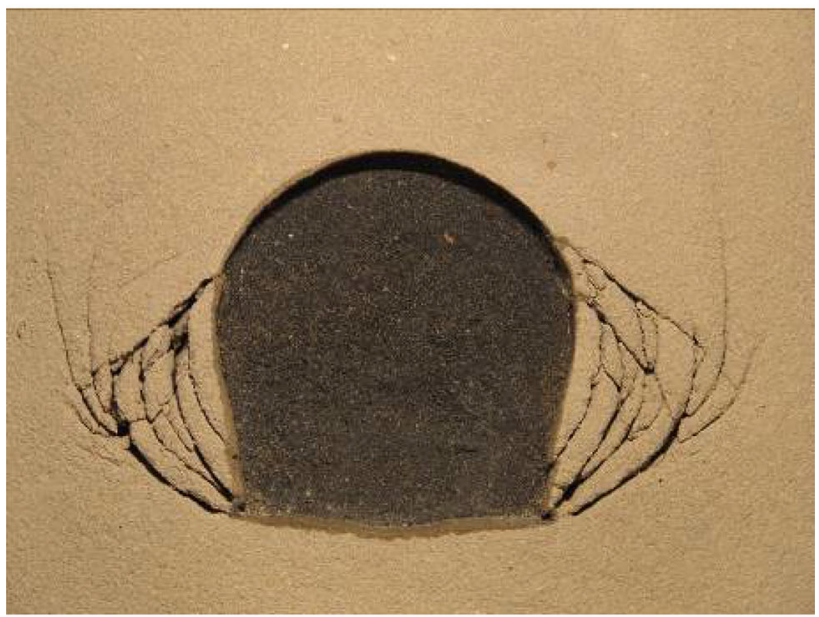

(b) M2

Fig. 5 Macroscopic fracture forms for the a M1 and b M2 models 


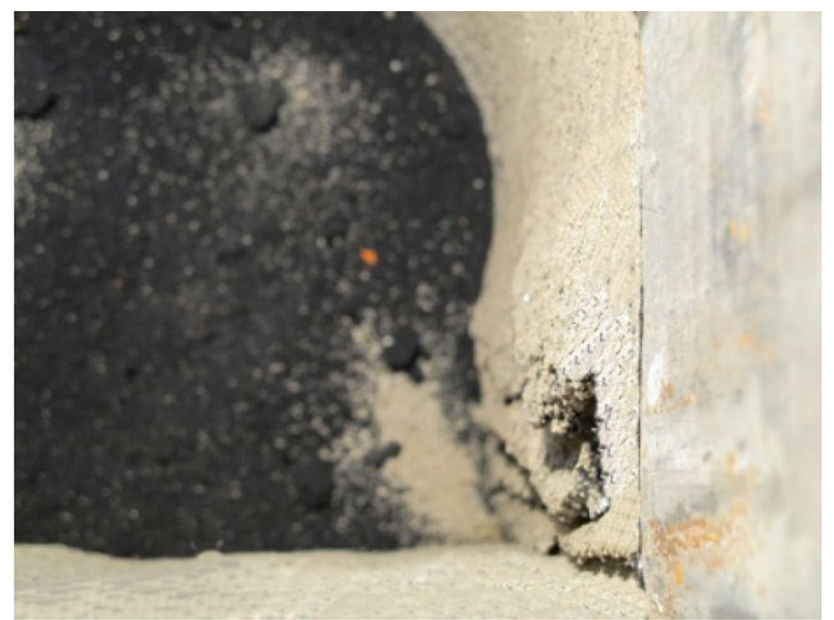

(a)

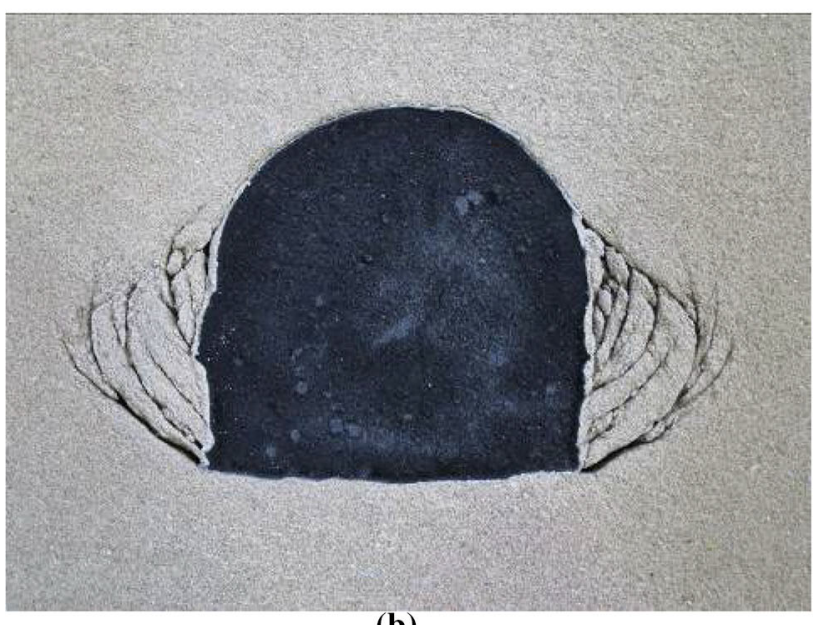

(b)

Fig. 6 Fracture form for the M3 model tunnel showing a the pressure stabilization process and $\mathbf{b}$ the macroscopic fracture form

collapsing. The macroscopic fracture form of the M3 model tunnel is shown in Fig. 6b.

As shown in Fig. 6b, after the crack was generated in the side wall, the curve extended upwards and inwards. When it reached a certain height, it met the inclined downward crack from the arch foot, which cut it off and stopped its continuous development. The inclined downward crack at the arch foot also stopped its extension and development.

\subsubsection{Cross section sizes for model tunnels after deformation}

The cross sections of the three model tunnels after deformation are shown in Fig. 7, and the deformation dimensions of the model tunnels are summarized in Table 2. It is seen that there was inner shrinkage in the tunnels of the M1 and M2 models, which gradually increased from the arch foot to the wall foot. The cross sections of the M1 and M2 models were both an inverted trapezoidal shape. There

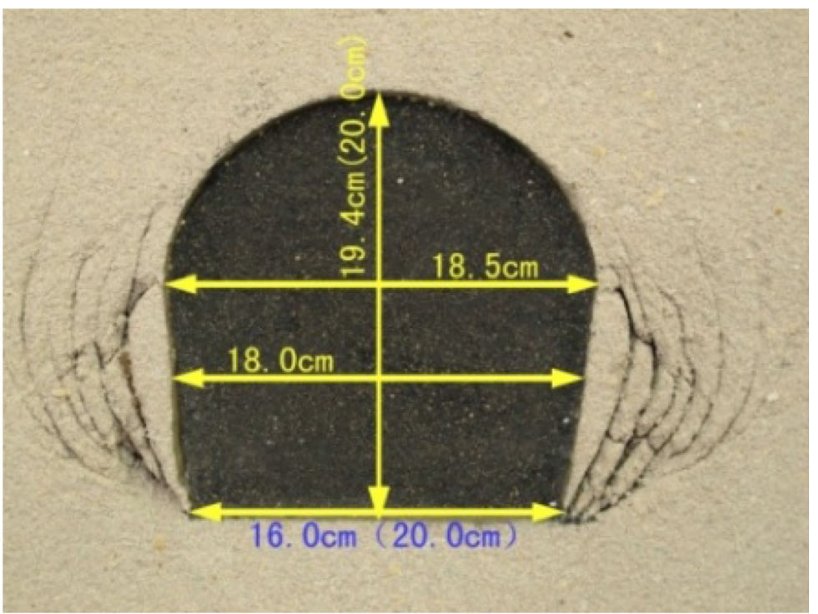

(a) M1

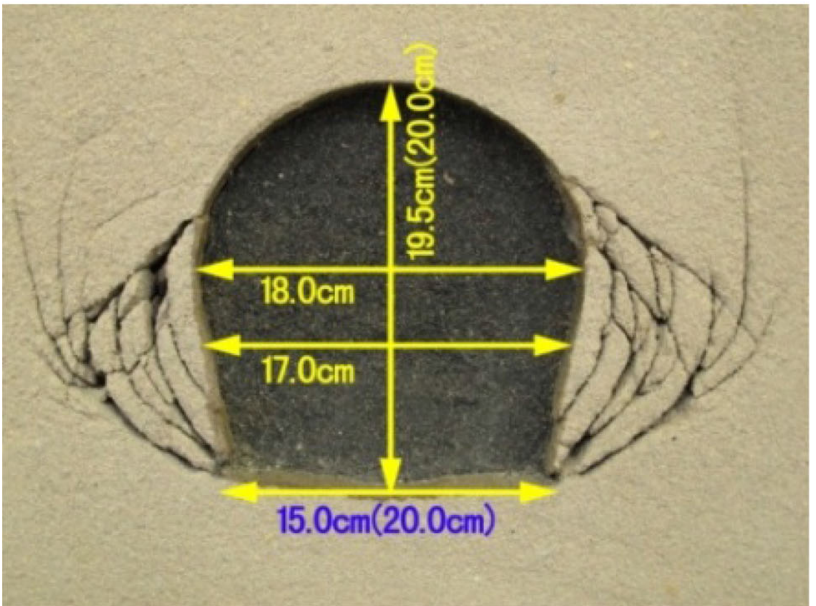

(b) M2

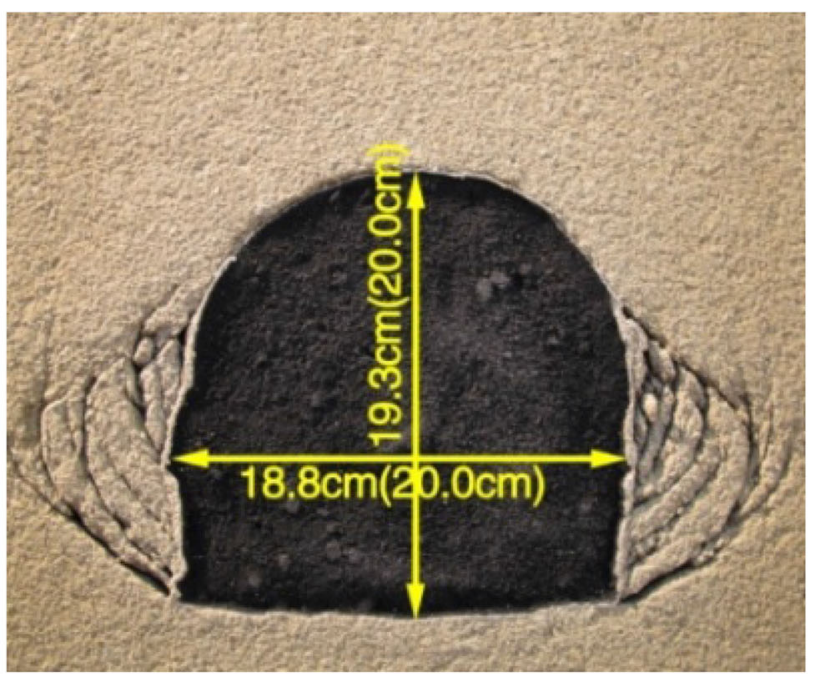

(c) $\mathrm{M} 3$

Fig. 7 Cross sections of the a M1, b M2, and c M3 model tunnels after deformation 
Table 2 Comparison of the deformation dimensions between the model tunnels

\begin{tabular}{|c|c|c|c|c|}
\hline Item & Deformation & M1 & M2 & M3 \\
\hline \multirow[t]{3}{*}{ Height of tunnel $(\mathrm{cm})$} & Before deformation & 20 & 20 & 20 \\
\hline & After deformation & 19.4 & 19.5 & 19.3 \\
\hline & Reduced value & 0.6 & 0.5 & 0.7 \\
\hline \multirow[t]{3}{*}{ Width in the middle of wall $(\mathrm{cm})$} & Before deformation & 20 & 20 & 20 \\
\hline & After deformation & 18 & 17 & 18.8 \\
\hline & Reduced value & 2 & 3 & 1.2 \\
\hline \multirow[t]{3}{*}{ Width of tunnel floor (cm) } & Before deformation & 20 & 20 & N/A \\
\hline & After deformation & 16 & 15 & N/A \\
\hline & Reduced value & 4 & 5 & N/A \\
\hline \multirow[t]{3}{*}{ Width between left and right arches $(\mathrm{cm})$} & Before deformation & 20 & 20 & N/A \\
\hline & After deformation & 18.5 & 18 & N/A \\
\hline & Reduced value & 1.5 & 2 & N/A \\
\hline
\end{tabular}

were no obvious deformations found in the arch and bottom plate of the three models, but the left and right side walls were significantly deformed. The roof and floor of the M3 model roadway did not have obvious deformation, but the left and right sides of the roadway were seriously deformed as shown in Fig. 7c. The deformation distances of the roadways for the three models are shown in Table 2.

\subsubsection{Crack range}

The crack ranges after deformation of the three model tunnels are shown in Figs. 8, 9, and 10. The widest part of the fracture for the left wall of the M1 model is located at the arch foot. The distribution width was from the arch foot and moved $90 \mathrm{~mm}$ outwards. The crack height was $140 \mathrm{~mm}$, and the fracture body width was between 3 and $20 \mathrm{~mm}$. The widest part of the crack for the right wall was located at the arch foot flat. The distribution width of the self-arch foot was outwards $90 \mathrm{~mm}$, the crack height was $150 \mathrm{~mm}$, and the fracture body width was between 3 and $20 \mathrm{~mm}$, as shown in Fig. 8.

The diagonal downward cracks of the left and right wall arch feet for the M2 model were well developed. The

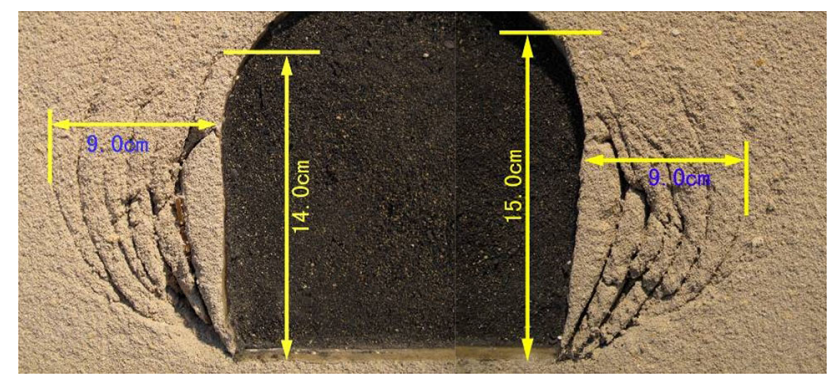

Fig. 8 Width and height of cracks on the left and the right side walls of the M1 model

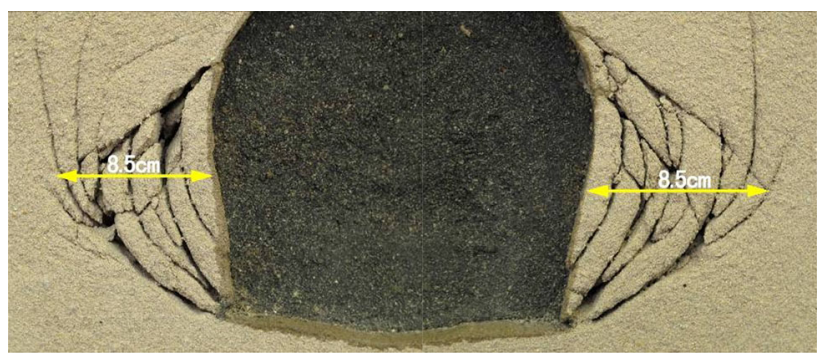

Fig. 9 Width of cracks in the M2 model

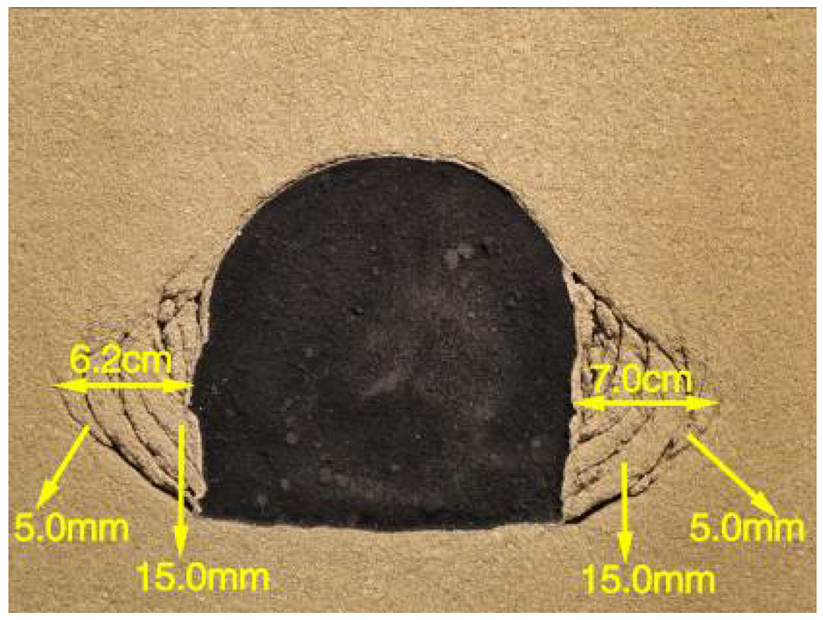

Fig. 10 Width of cracks in the M3 model

wedge-shaped cracks that formed from the upwards cracks of the self-wall feet were more obvious. The horizontal distance between the left and right cracks on the same horizontal line with the arch foot was $85 \mathrm{~mm}$, as shown in Fig. 9.

The cracks are intuitively seen from Figs. 8, 9, 10 and Table 3. All cracks occurred at the side walls after the 
deformations of the three model tunnels. The breakpoints were not all at the foot of side walls but were arranged up in turn with a certain distance. After the cracks occurred at the tunnel floors, they extended upwards and inwards in curved shapes, and at a certain height they met the slanting downward cracks that appeared at the arch feet. Finally, the cracks stopped their development, and the entire damage range of the model tunnels were formed. It is also seen from Table 3 that the width of the split bodies for the model tunnels (i.e., annular zonal disintegration area) increased with the load.

In the course of adding a load, destruction never occurred after excavation in the M1 model tunnel. The cracks parallel to the tunnel axis were generated after excavation at the feet of the left and right side walls in the M2 and M3 models. The cracks in the surrounding rocks of the test models were all initially generated at the feet of the side walls before expanding upwards and outwards. The cracks were all in the form of slip lines and finally intersected the side walls at the arch feet. The widths of the model tunnels increased after the cracks were generated. Each crack in the surrounding rock of the test models corresponded to a boundary load value, and the annular broken area was formed in the surrounding rock; that is, the phenomenon of zonal disintegration appeared.

\subsection{Results analysis for tunnel strain tests}

The strain test results from the top of the vaults, the middle part of the side walls, and the bottom of the tunnels of the three models were analyzed after excavation and under maximum load conditions. The strain was positive under tension and negative under pressure. In the following figures, the points are the actual values of each measurement, the dashed line is the fitting curve, the parameter $r / D$ is the ratio of the distance between the measurement of the side wall to the width of the tunnel, $\varepsilon_{r}$ is the radial strain, and $\varepsilon_{\theta}$ is the circumferential strain.

\subsubsection{Comparative analysis of strains for three models after excavation}

(1) Comparative analysis of the radial and circumferential strains at the top of the vaults in the three models after excavation The radial and circumferential strain curves at the top of vaults from the three models after excavation are shown in Fig. 11. From Fig. 11a, the radial strain of the three models appears logarithmic based on the data fitting. The tensile strain for the M1 model was near the tunnel wall while the compressive strain was far from the tunnel wall. The strain began to enter the tension state when $r / D$ was approximately 0.2 , and the maximum tension strain appeared near the tunnel wall. The M2 and M3 models were in a compression state, and the strain far from the tunnel wall was larger than in other places. In Fig. $11 \mathrm{~b}$, the circumferential strains for the M1 and M2 models were logarithmic based on the data fitting. The circumferential strain data for the M3 model were dispersed and the strain values were in a state of fluctuation. This was because the tunnel load increased gradually during excavation and the strain for the plastic medium in the rock mass would be adjusted continuously.

To transform the data to be non-discrete, the monitoring data in the article were fit logarithmically. The fitting formula is:

$\varepsilon=A \ln \frac{r}{D}-B$

where $\varepsilon$ is the strain, $r / D$ is the ratio of the distance between the measured point and the side wall to the width of the tunnel, $A$ and $B$ are fitting constants.

(2) Comparative analysis of the radial and circumferential strains in the middle part of the side walls in three models after excavation The radial and circumferential strain curves in the middle part of the side walls in the three models after excavation are shown in Fig. 12. As seen from the fitting curves in Fig. 12a, the trend in the radial strain for the middle part of the side walls in the three models was nearly consistent with that at the top of the vaults, and the strain value decreased rapidly with $r / D$. The radial strains of the M1 model were all tension, and the maximum value

Table 3 Width data of the cracks in the three arch models

\begin{tabular}{|c|c|c|c|c|c|}
\hline \multirow[t]{2}{*}{ Model } & \multicolumn{2}{|c|}{ Width of crack $(\mathrm{cm})$} & \multicolumn{2}{|c|}{ Height of crack $(\mathrm{cm})$} & \multirow[t]{2}{*}{ Split body width $(\mathrm{cm})$} \\
\hline & Left side wall & Right side wall & Left side wall & Right side wall & \\
\hline M1 & 9.0 & 9.0 & 14 & 15 & $0.2-0.3$ \\
\hline M2 & 8.5 & 8.5 & 14 & 14 & $0.3-0.5$ \\
\hline M3 & 6.2 & 7.0 & 13.5 & 13.6 & $0.5-1.5$ \\
\hline
\end{tabular}




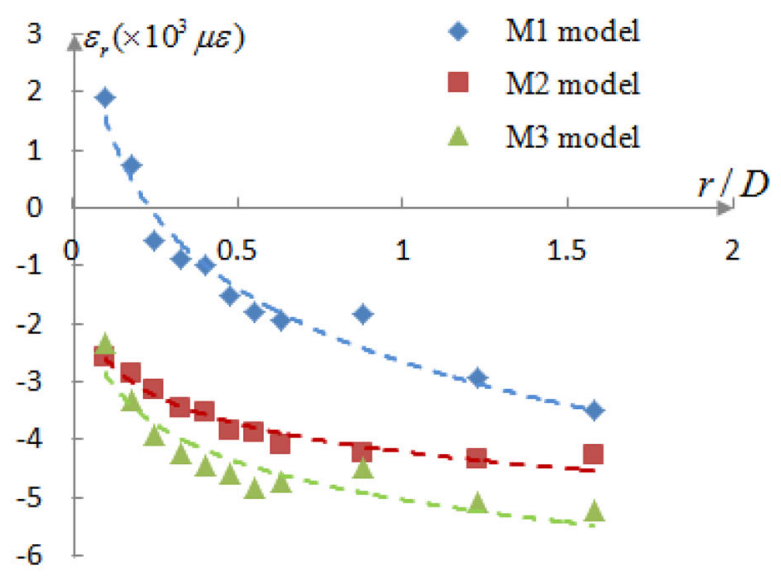

(a)

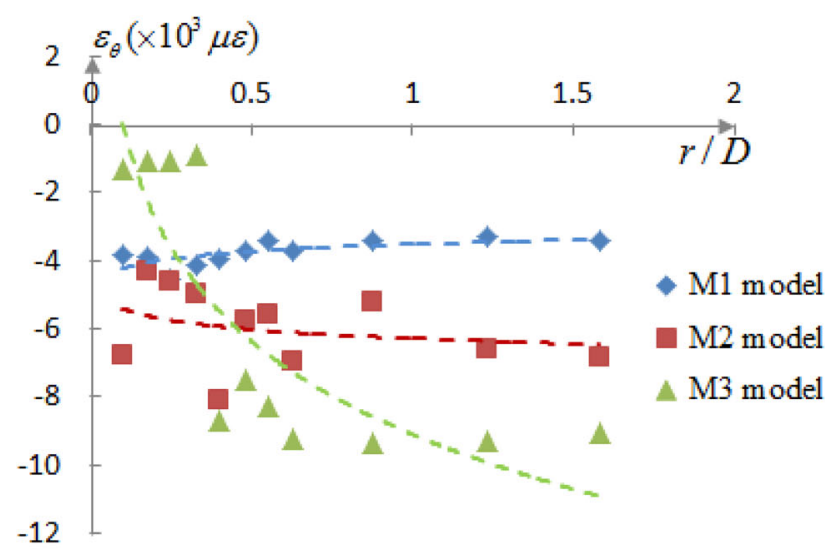

(b)

Fig. 11 Comparative analysis of the $\mathbf{a}$ radial and $\mathbf{b}$ circumferential strains at the top of the vaults for the three models after excavation

was approximately 3.6 times that of the minimum value. Compression strain appeared in the M2 and M3 models when $r / D$ was 1.23 . From the fitting curves in Fig. $12 \mathrm{~b}$, the circumferential strain values in the middle part of the side walls for the three models were all in a compression strain state, and the measured data of the circumferential strains barely deviated from the fitting curve, which indicates the mechanical properties of the surrounding rocks in three models were consistent. The circumferential strain for the M1 model decreased rapidly with $r / D$, and the variations in the circumferential strain for the M2 and M3 models were relatively smooth without mutability.

(3) Comparative analysis of the radial and circumferential strains at the bottom of the tunnels in the three models after excavation The radial and circumferential strain curves at the bottom of the tunnels in three models after excavation are shown in Fig. 13. In Fig. 13a, the radial strain of each measurement in the three models increased with $r / D$ and tended to be gradually stable. The surrounding rock of the tunnel floor was almost always in the compression strain

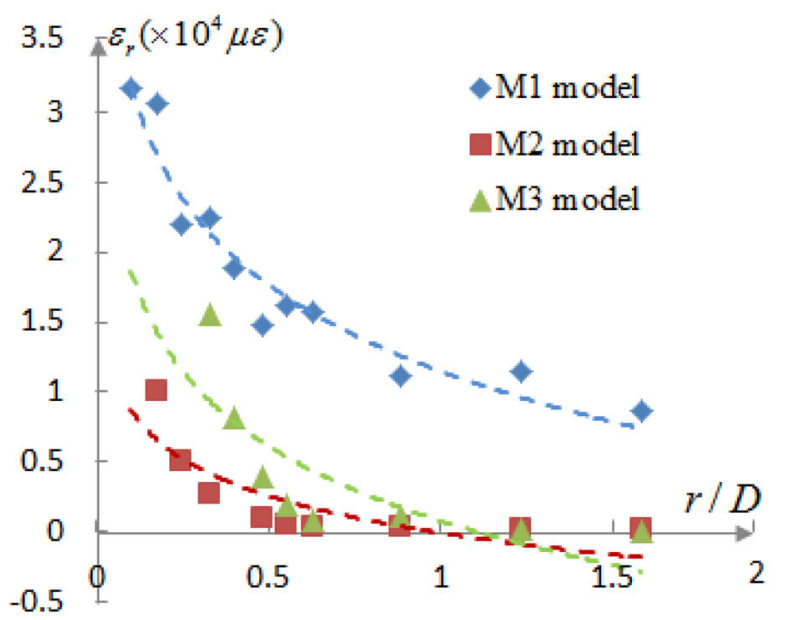

(a)

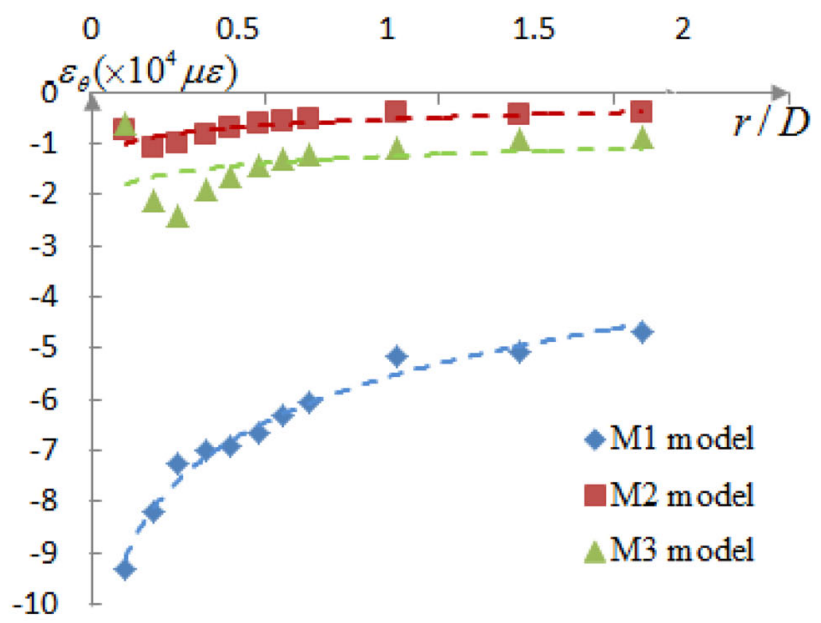

(b)

Fig. 12 Comparative analysis of the a radial and $\mathbf{b}$ circumferential strains in the middle part of side walls in the three models after excavation

state, and it was only possible to be in a tension strain state at the bottom of the tunnel. This showed that the supporting role of the tunnel floor was relatively weak and very easy to destroy. As seen from the fitting curves of Fig. 13b, the circumferential strain at the bottom of the tunnels in the three models was mostly in compression, and the strain values were scattered with a poor regularity, which results in some unrealistic data. The circumferential strain values tended to be stable at greater distances from the bottom of the tunnel, but with significant differences close to the tunnel floor. The circumferential strain of the M1 model was the largest close to the tunnel floor, which indicates that the supporting effect of the tunnel floor in the M1 model was large. The circumferential strain decreased and had an upwards tendency of development in the M2 and M3 models, which indicates that the rock around the tunnel bottom for the M2 and M3 models might be destroyed. 


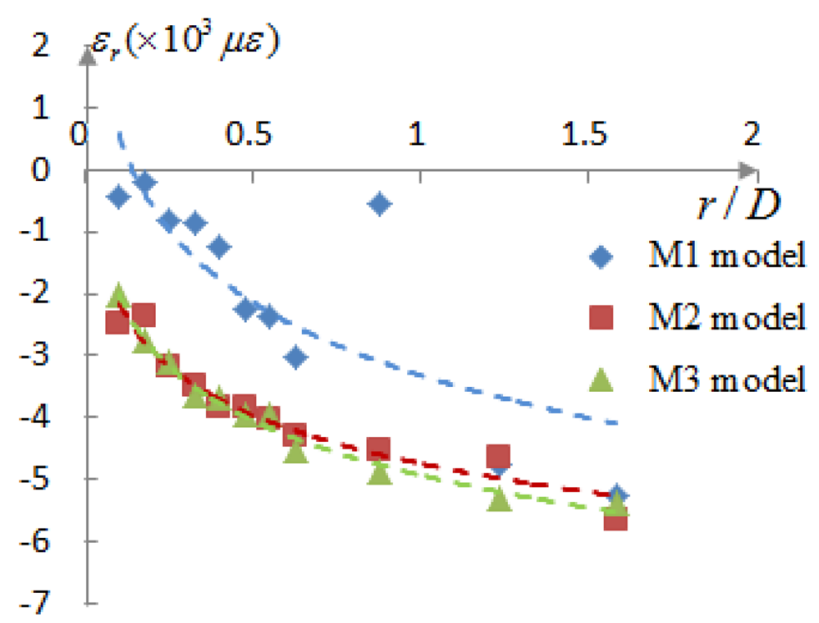

(a)

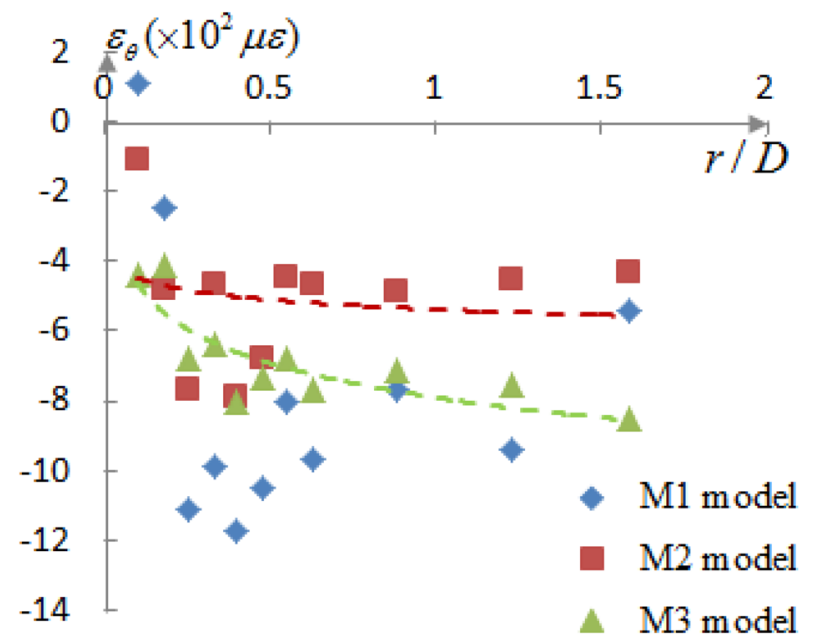

(b)

Fig. 13 Comparative analysis of the a radial and $\mathbf{b}$ circumferential strains at the bottom of the tunnels in three models after excavation

Combined with the tunnel damage results analysis, a comprehensive comparison was performed for the strain test results at the top part of the vaults, the middle part of side walls, and the bottom of the tunnel floors in the three models after excavation. It was readily found that the phenomenon of zonal disintegration appeared in the three models under a load. The radial tension strain was the fundamental cause of circular cracks in the surrounding rock of the tunnels. The damage to the M3 model tunnel was the most serious and the M1 model tunnel was the lightest. The tunnel cracks all extended outwards from the arch foot of the side walls, which split the bodies with different widths.

\subsubsection{Comparative analysis of strains for the three models under the maximum load}

As the M3 model tunnel must be stabilized after excavation, the strain value changed slowly during the pressure stabilization process, and the trend was nearly the same as that under a load. Therefore, the strain values under a maximum load for the M3 model were not analyzed in Figs. 14, 15, 16. Only the strain test results under the maximum load of the M1 and M2 models were analyzed.

(1) Comparative analysis of the radial and circumferential strains at the top of the vaults in the M1 and M2 models under maximum load The radial and circumferential strain curves at the top of the vaults in the M1 and M2 models under a maximum load are shown in Fig. 14. From the fitting curves in Fig. 14a, the radial strains at the top of the vaults in the M1 and M2 models were almost always compression strain under the maximum load. The strain

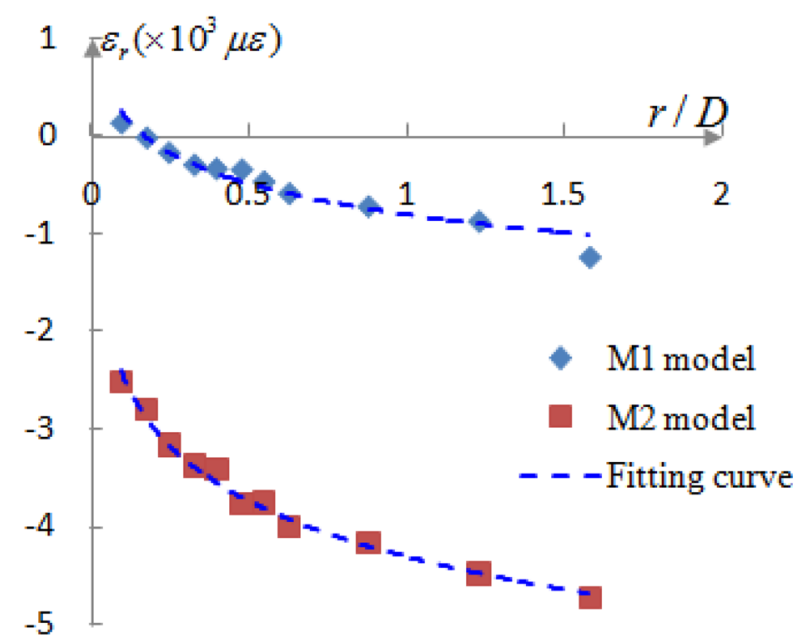

(a)

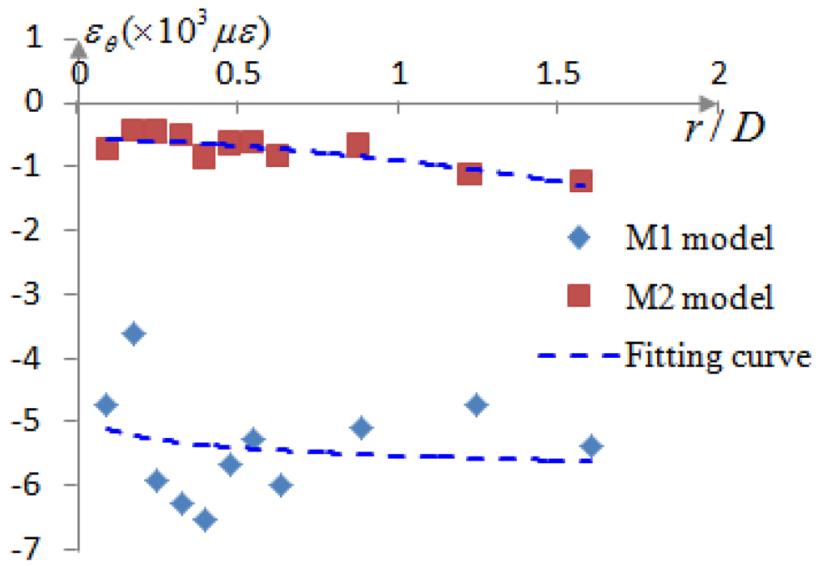

(b)

Fig. 14 a Radial and b circumferential strain curves at the top of the vaults in the M1 and M2 models under the maximum load 


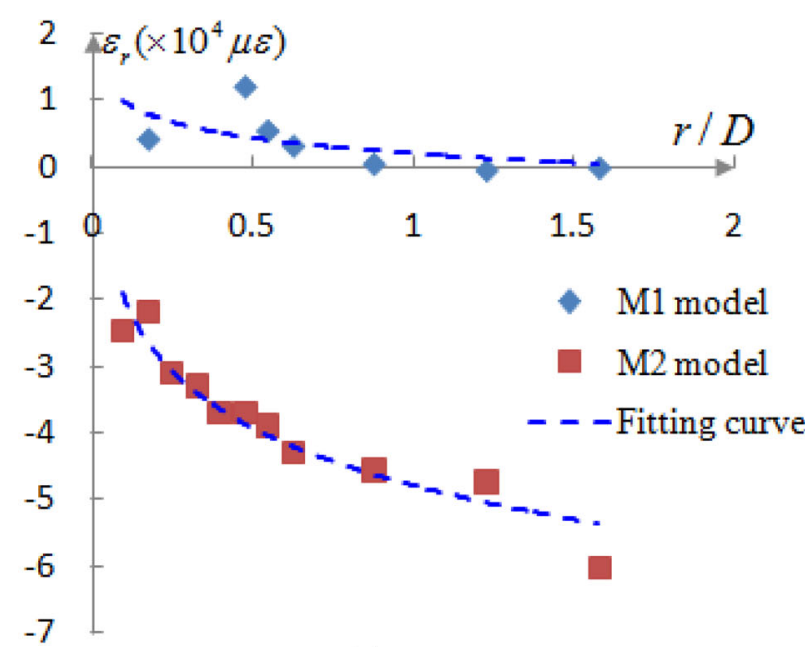

(a)

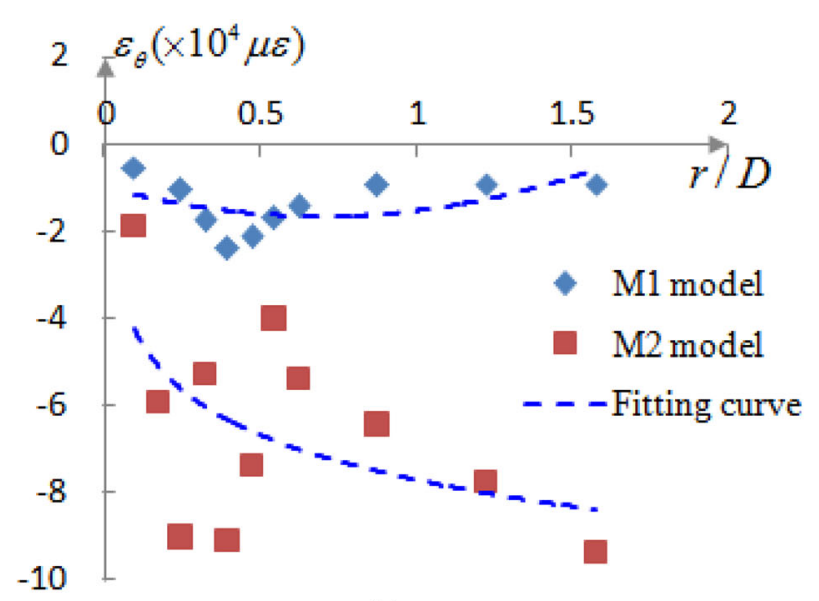

(b)

Fig. 15 a Radial and b circumferential strain curves in the middle part of the side walls in the M1 and M2 models under the maximum load

values increased with distance from the vault and gradually tended to be stable, which increased significantly compared with the loaded conditions. The radial strain values for the two models had an upwards trend in the near-tunnel vault because the compression strains were converted to tension strains. As seen from the fitting curves in Fig. 14b, the circumferential strains at the top of the vaults in the M1 and M2 models were also compression strains under the maximum load. The strain values were slightly larger than at the corresponding positions compared with the loaded conditions. Due to differences in the maximum loads between the M1 and M2 models, the circumferential strains of the two models differed greatly. In the process of adding the maximum load in the M1 model, the medium near the vault entered a plastic state, causing the strain near the wall to flicker. The stability of the M2 model was relatively good when adding the maximum load, and the circumferential strains only deviated slightly from the fitting curve.

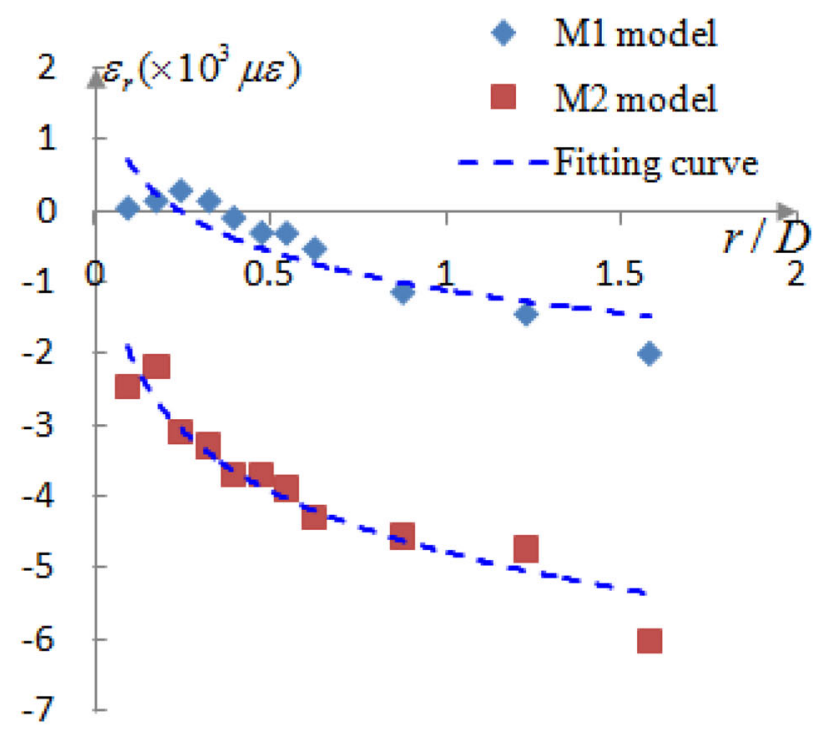

(a)

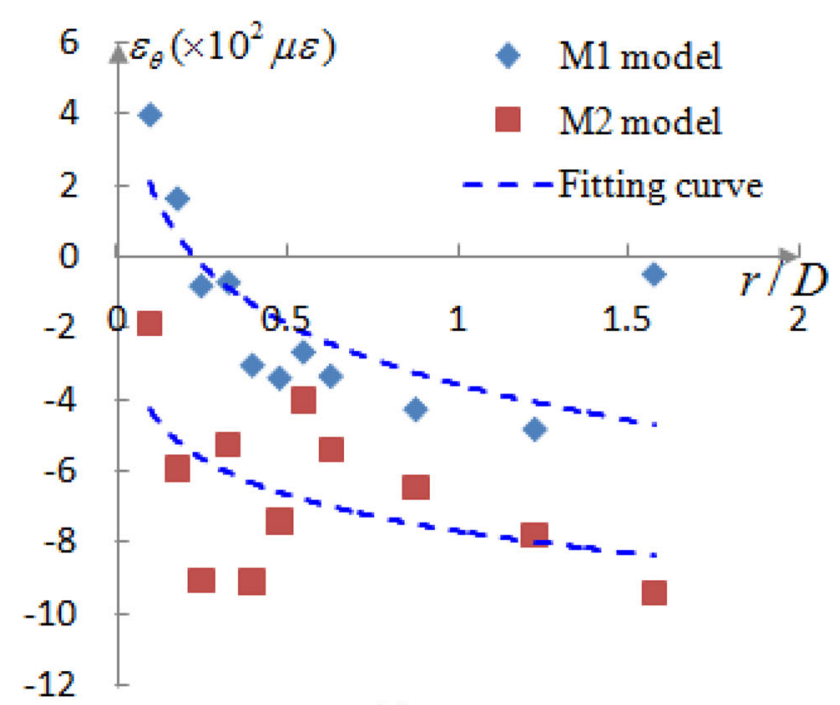

(b)

Fig. 16 a Radial and b circumferential strain curves at the bottom part of the tunnels in the M1 and M2 models under the maximum load

(2) Comparative analysis of the radial and circumferential strains in the middle part of the side walls in the MI and M2 models under the maximum load The radial and circumferential strain curves in the middle part of the side walls in the M1 and M2 models under the maximum load are shown in Fig. 15. From the fitting curves in Fig. 15a, the radial strains in the middle part of the side walls in the M1 model were in tension under maximum load conditions, while that in the middle part of the side walls in the M2 model were in compression. The radial strain values for the M1 model decreased rapidly with $r / D$ before finally becoming stable. The absolute values of radial strain for the M2 model increased gradually with $r / D$ with a very clear trend. 
As seen from the fitting curves in Fig. 15b, the circumferential strains in the middle part of the side walls in the M1 and M2 models were all compression strains under maximum load conditions. However, the strains were scattered and the measured data were inconsistent with the fitting curve. This shows that the medium in the middle part of side walls in the two models entered a plastic state in the course of adding the maximum load, which resulted in a flickering strain near the wall. This also reflects the possible destruction of the surrounding rock in the middle part of the side walls for the two models.

\section{(3) Comparative analysis of the radial and circumferential} strain at the bottom part of the tunnels in the M1 and M2 models under the maximum load

The radial and circumferential strain curves at the bottom part of the tunnels in the M1 and M2 models under the maximum load are shown in Fig. 16. As seen from the fitting curves in Fig. 16a, the radial strains at the bottom part of the tunnels in the M1 and M2 models under the maximum load increased with $r / D$ before finally stabilizing. In the vicinity of the tunnel floor, the radial strains of the M1 model were under tension, and those of the M2 model were under compression but with a tendency to become tension. This shows that the probability of tunnel floor damage also increased with a greater load. Based on the fitting curves in Fig. 16b, the circumferential strains for the M1 model were extended in the range of the tension strain state under the maximum load but were still located near the tunnel floor. However, the circumferential strain data for the M2 model were dispersed. This was because the surrounding rock of the tunnel floor gradually entered the plastic state with an increased load, which caused the circumferential strain to flicker. This also suggests the possible destruction of the tunnel floor for the M2 model.

Combined with the tunnel damage results analysis, a comprehensive comparison was performed for the strain test results at the top of the vaults, the middle part of the side walls, and the bottom of the tunnel floors in the three models under the maximum load. It is concluded that the radial tension strain was the main cause of circular cracks in the surrounding rock of the tunnels. Meanwhile, the tensile fracture was the key to the occurrence of zonal disintegration in the surrounding rock.

\section{Conclusions}

(1) It was found that the phenomenon of zonal rupture appeared in the three models, and the damage for the M3 model tunnel was the most significant, while that for the M1 model tunnel was the least serious. Under a load, fracturing occurred primarily in the surrounding rock adjacent to the side wall of the model tunnel. Under the maximum load, fracturing occurred primarily in the surrounding rock of the model tunnel. These can be because the load added after excavation was carried primarily by the rock mass, which was deep and away from the tunnel wall. Thus, the damage was transferred from the vicinity of the wall to the deeper parts. After the excavation tunnel was stabilized, the damage to the surrounding rock was no longer delivered to the deeper parts. With an increasing maximum load, the annular damage range enlarged, but the phenomenon of zonal disintegration did not extend indefinitely. When the new fault surface formed by the surrounding rock of the model tunnel was sufficiently large, the damage range again spread out.

(2) The radial tension strain of the surrounding rock was the fundamental reason for the circular failure of the tunnel. This was found from the data fitting analysis of the radial and the circumferential strains of the surrounding rocks. When the radial strain was greater than its ultimate tension strain, the surrounding rock has been damaged.

(3) The formation of the tensile fracture surface was equivalent to the formation of a cavity with an enlarged radius in the original surrounding rock. Under the action of an increasing load, tensile cracks appeared around the new cavern. As a result, the tensile and shear failures of the surrounding rock caverns would be repeated under large loads; thus, the zonal disintegration phenomenon that exists alternately between the broken area and the original area would be formed. In addition, the circumferential strain of the model tunnels were scattered, their regularities were poor, and they all consisted of compression strains, which had little effect on the model tunnel damage. The presented test results are in agreement with previous studies.

(4) The experimental models were placed horizontally in the test device, the axial direction of each model tunnel was vertically upwards, and the influence of the model's own weight on the deformation of the tunnel was ignored. However, the Froude similarity criterion was adopted in the tests, which reduced the influence of gravity on the surrounding rock tunnel to some extent. Additionally, the complexity of the geological conditions made it difficult to achieve comprehensive and accurate simulations of the actual tunnel conditions. The effects of poor geological factors, such as joints, faults, and groundwater, on the fracturing of the surrounding rock roadway were not considered. However, this can be used as a research object for future steps to 
understand the fracture mechanism of the surrounding rock tunnel.

\begin{abstract}
Acknowledgements This work was financially supported by the Chinese National key R \& D project (No. 2016YFC0801402) and the Chinese National Natural Science Foundation Project (No. 51627804).
\end{abstract}

\section{Compliance with ethical standards}

Conflicts of interest The authors declare no conflicts of interest.

Open Access This article is licensed under a Creative Commons Attribution 4.0 International License, which permits use, sharing, adaptation, distribution and reproduction in any medium or format, as long as you give appropriate credit to the original author(s) and the source, provide a link to the Creative Commons licence, and indicate if changes were made. The images or other third party material in this article are included in the article's Creative Commons licence, unless indicated otherwise in a credit line to the material. If material is not included in the article's Creative Commons licence and your intended use is not permitted by statutory regulation or exceeds the permitted use, you will need to obtain permission directly from the copyright holder. To view a copy of this licence, visit http://creativecommons. org/licenses/by/4.0/.

\section{References}

Adams GD, Jager AJ (1980) Petroscopic observations of rock fracturing ahead of stope faces in deep-level gold mines. J S Afr Inst Min Metall 80(6):204-209

Chen HX (2016) Numerical research for nonlinear continuous phase transition model of zonal disintegration of rock masses near deep-level tunnels. Beijing University of Civil Engineering and Architecture, Beijing

Chen XG, Zhang QY, Wang Y, Li SC, Wang HP (2013) In situ observation and model test on zonal disintegration in deep tunnels. J Test Eval 41(6):990-1000

Chen HX, Qi QZ, Li KR, Xu C, Liu TT (2017) Nonlinear continuous phase transition model for zonal disintegration of rock masses around deep tunnels. Rock Soil Mech 38(4):1032-1040

Chen X, Zhang N, Ma T (2018) Energy-based forming and anchoring mechanism and criterion for zonal disintegration. Theoret Appl Fract Mech 97:349-356

Fang ZL (1984) Study on the ground pressure and control method for opening in soft and broken rocks in Jin Chuan Mine No. 2. J Beijing Univ Iron Steel Technol 1:1-20

Feng XT, Pei SF, Jiang Q (2017) Deep fracturing of the hard rock surrounding a large underground cavern subjected to high geostress: in situ observation and mechanism analysis. Rock Mech Rock Eng 50(8):2155-2175

Gao FQ, Kang HP, Lin J (2010) Numerical simulation of zonal disintegration of surrounding rock mass in deep mine roadways. J China Coal Soc 35(1):21-25

Geng MS (2010) Numerical tests on mechanism of zonal disintegration in deep tunnels. Dalian University of Technology, Dalian

Guzev MA, Paroshin AA (2001) Non-Euclidean model of the zonal disintegration of rocks around an underground working. J Appl Mech Tech Phys 42(1):131-139

Li SC, Wang HP, Qian QH, Fan QZ, Zhang QS (2008) In-situ monitoring research on zonal disintegration of surrounding rock mass in deep mine roadways. Chin J Rock Mech Eng 27(8):1545-1553
Li SC, Wang JH, Chen WZ (2016) Study on mechanism of macro failure and micro fracture of local nearly horizontal stratum in super-large section and deep buried tunnel. Geomech Eng 11(2):253-267

Mirenkov VE (2014) Zonal disintegration of rock mass around an underground excavation. J Min Sci 50(1):33-37

Qian QH, Li SC (2008) A review of research on zonal disintegration phenomenon in deep rock mass engineering. Chin J Rock Mech Eng 27(6):1278-1284

Qian QH, Zhou XP (2011) Non-euclidean continuum model of the zonal disintegration of surrounding rocks around a deep circular tunnel in a non-hydrostatic pressure state. J Min Sci 47(1):37-46

Qian QH, Zhou XP, Yang HQ, Zhang YX, Li XH (2009) Zonal disintegration of surrounding rock mass around the diversion tunnels in Jinping II Hydropower Station, Southwestern China. Theor Appl Fract Mech 51(2):129-138

Qian Q, Zhou X, Xia E (2012) Effects of the axial in situ stresses on the zonal disintegration phenomenon in the surrounding rock masses around a deep circular tunnel. J Min Sci 48(2):276-285

Reuter M, Krach M, Kießling U, Krach V (2015) Zonal disintegration of rocks around breakage headings. J Min Sci 51(2):237-242

Shemyakin EI, Fisenko GL, Kurlenya MV, Oparin VN, Kuznetsov YS (1986) Zonal disintegration of rocks around underground workings, part 1: data of in situ observations. Soviet Min 22(3):157-168

Shou YD, Zhou XP, Qian QH (2017) Dynamic model of the zonal disintegration of rock surrounding a deep spherical cavity. Int $\mathbf{J}$ Geomech 17(6):1-11

Shou YD, Zhou XP, Qian QH (2018) A critical condition of the zonal disintegration in deep rock masses: strain energy density approach. Theor Appl Fract Mech 97:322-332

Song HF (2012) The mechanism of zonal disintegration of deep rock masses. Chongqing University, Chongqing

Wang S (2016) Study on numerical simulation of zonal disintegration of surrounding rock in deep roadway. Qingdao University of Technology, Qingdao

Wang X, Pan Y, Zhang Z (2013) A spatial strain localization mechanism of zonal disintegration through numerical simulation. J Min Sci 49(3):357-367

Wang HP, Li SC, Xue JH, Li JM, Ma QY (2014) Control methods of stability of zonal disintegration surrounding rock in deep rock roadway and its application. Rock Soil Mech 35(7):1957-1964

Yuan L, Gu JC, Xue JH, Zhang XY (2014) Model test research on the zonal disintegration in deep rock. J China Coal Soc 39(6):987-993

Zhang ZH, Pan YS (2015) Three-Dimensional similar material experimental study on zonal disintegration of deep tunnel failure. J China Coal Soc 40(12):2780-2786

Zhang YX, Zhang BH (2011) Mechanism of zonal disintegration in surrounding rock mass around deep rock engineering and its application. Sci China Technol Sci 54(S1):221-227

Zhang QY, Zhang XT, Xiang W, Chen XX, Xu X (2013) Model Test study on the effect of different cavity shape and loading Mode on zonal disintegration of Deep Rock Mass. Chin J Rock Mech Eng 32(8):1564-1571

Zhou XP, Qian Q (2013) Zonal disintegration mechanism of the microcrack-weakened surrounding rock mass in deep circular tunnels. J Min Sci 49(2):210-219

Zhou XP, Qian QH, Zhang BH, Zhang YX (2010) The zonal disintegration mechanism of surrounding rock in deep buried spherical cavern. Eng Mech 27(1):69-75+90

Zhou XP, Bi J, Qian QH (2013) The zonal disintegration mechanism of isotropic rock masses around a deep circular tunnel subjected to dynamic unloading. Chin J Solid Mech 34(4):352-360 